\title{
Exposure of the Population of Ngaoundere-Cameroon to Ionizing Radiation Related to Medical Diagnosis in 2018
}

\author{
Mathurin Neossi Guena1,2*, Baudouin Djoumessi Nanfack¹, Joseph Gonsu Fotsing3,4 \\ ${ }^{1}$ Department of Biomedical Sciences, Faculty of Sciences, University of Ngaoundéré, Ngaoundéré, Cameroon \\ ${ }^{2}$ Imaging Service, Ngaoundéré Regional Hospital, Ngaoundéré, Cameroon \\ ${ }^{3}$ Faculty of Medicine and Biomedical Sciences, University of Yaounde I, Yaounde, Cameroon \\ ${ }^{4}$ Yaounde Gynaecology Obstetrics and Pediatrics Hospital, Yaounde, Cameroon \\ Email: *mneossiguena@yahoo.fr
}

How to cite this paper: Guena, M.N. Nanfack, B.D. and Fotsing, J.G. (2019) Exposure of the Population of Ngaoundere-Cameroon to Ionizing Radiation Related to Medical Diagnosis in 2018. Open Journal of Radiology, 9, 125-138. https://doi.org/10.4236/ojrad.2019.92012

Received: April 13, 2019

Accepted: June 16, 2019

Published: June 19, 2019

Copyright $\odot 2019$ by author(s) and Scientific Research Publishing Inc. This work is licensed under the Creative Commons Attribution International License (CC BY 4.0).

http://creativecommons.org/licenses/by/4.0/

\begin{abstract}
Background: Medical applications are the main source of exposure to ionizing radiation of human origin. Our objective was to determine the data on exposure to ionizing radiation of medical origin of the population of Ngaoundéré in 2018. Methodology: It was a cross-sectional descriptive study conducted within a period of one year, in the different hospitals of Ngaoundéré, with a functional medical imaging service. The variables studied were age, sex, type of examination, anatomical region and effective dose. The statistical analysis was performed using the Microsoft Office 2016 software, Sphinx V5; the effective dosage was calculated using the Internet Dose calculation Module. Results: In 2018, 4136 diagnostic acts using ionizing radiation were carried out; it concerned only conventional radiology with an average of 0.02 per capita. The total collective dose received by the population was $8300 \mathrm{mSv}$, and an average dose of $0.040 \mathrm{mSv}$ per inhabitant. The proportion of the population that has actually benefited from a conventional radiology examination is $2.07 \%$, an individual effective average dose of $2 \mathrm{mSv}$. The most frequent acts involved the thorax, limbs, spine and pelvis with respectively $53.9 \%$; $19.6 \%$; $14.3 \%$ and $6.7 \%$. Acts involving the spine, pelvis and hip, skull and abdomen contributed to the majority of the collective effective dose respectively with $45.75 \%, 25.96 \%, 10.53 \%$ and $8.84 \%$. The age group performing most exams in men is 25 to 49 and 25 to 54 in women; the number of acts is higher among men 2457 (59.4\%) acts compared to women 1679 (40.6\%) acts. The collective dose per sex is higher among women with $4487.22 \mathrm{mSv}$ (54.06\%) compared to men with $3812.98 \mathrm{mSv}$ (45.94\%). Conclusion: Only $2.07 \%$ of population of Ngaoundere benefited from a conventional radiology examination in 2018
\end{abstract}


with an individual effective average dose of $2 \mathrm{mSv}$. The annual per capita number of acts is 0.02 and annual per capita effective dose is $0.040 \mathrm{mSv}$ in Ngaoundéré in 2018.

\section{Keywords}

Exposure, Ionizing Radiation, Conventional Radiology, City of Ngaoundéré, 2018

\section{Introduction}

Medical applications are by far the largest source of exposure to ionizing radiation of human origin. Thus, diagnostic procedures account for more than $97 \%$ of artificial exposure and nearly $26 \%$ of total exposure of the population [1]. This exposure leads to absorption by the subject in contact with a dose likely to induce harmful biological effects on the body which are of two types, the so-called deterministic short-term effects directly related to cellular lesions for which a threshold of appearance has been defined and the so-called stochastic long-term or random effects which are dominated by cancers and genetic anomalies and can develop from few hours to several years [1]. It would therefore be important to regularly estimate this medical exposure and analyze its evolution over time. A recent publication on the exposure of the population to ionizing radiation in the United States points out that medical exposure per year and per individual has increased six-fold, since the 1980s [2]. Directive 97/43/Euratom [3] states in Article 12 on the estimation of doses received by the public: "Member States shall ensure that the distribution of individual doses generated by exposures for medical purposes is determined for the population and for the reference groups concerning it, depending on whether the Member States deem it necessary". The current revision of Directive 96/29/Euratom [4] on basic radiation protection standards should introduce an additional requirement: "Member States shall ensure that the distribution of individual doses due to medical exposure is determined and takes into account the age and sex distribution of the exposed population".

In recent years, many actions, both at European and American level, have been initiated in order to harmonize methods of collecting information and thus to have reliable indicators on the medical exposure of the population.

This is the case of the European Union's Dose Datamed project (2005-2007) which led to the publication of the report "radiation protection No. 154: European guidance on estimating population doses from medical $\mathrm{x}$-ray procedures (2008)" [5] and the "International action plan for the radiological protection of patients" action plan led by the International Atomic Energy Agency (IAEA). Great Britain is undoubtedly the country that has done the most in this field because; in the late eighties, the National Radiological Protection Board (NRPB) set up a national system of dose evaluation. By type of examination based on 
measurement campaigns conducted by a sentinel network of hospital services. Other countries, such as the Netherlands, Switzerland or Norway, also rely on annual activity data from all or some hospitals. For several years now, the fleet of heavy imaging equipment has expanded in Cameroon, with the creation of multiple imaging centers for public and private purposes therefore, an increase in examinations and protocols, with the result of irradiation of the population. However, the global exposure of the population to ionizing radiation of medical origin has never been evaluated in our country in general and in Ngaoundere in particular despite the creation of the National Radiation Protection Agency in 2002 with the primary mission of protecting people, goods and the environment against ionizing radiation [6].

It is also responsible for the dosimetry of patients, professionals, the public, the environment in the imaging services. This is why it is necessary to set up a long-term system to monitor practices both from the point of view of the knowledge of the nature, the frequency and the distribution of examinations in the population, then from the point of view of doses given to patients during these examinations. Thus, we proposed to conduct this pilot study to evaluate the medical exposure of the population of Ngaoundéré to ionizing radiation of medical origin in 2018, which could be the start point for monitoring these populations.

\section{Method}

The study was carried out in the two Hospitals with medical imaging departments equipped with ionizing radiation equipment in the city of Ngaoundéré, namely the medical imaging department of the Regional Hospital and clinic the Patience. This was a descriptive cross-sectional study, conducted within a period of one year, from January to December 2018, including all patients coming to perform a medical imaging examination, using ionizing radiation. The diagnostic acts selected for the study were those of conventional radiology, which are the only ones currently performed in the city of Ngaoundere and grouped according to the anatomical zone explored. Finally, 25 areas were defined for this study. The variables studied were the frequencies of diagnostic procedures by anatomical region, age, sex, examination required, anatomical region, indication of examination, irradiation parameters and irradiation dose. The collection took place in the imaging centers over a period of one year. The extrapolation of the results of the survey sample to the general population was based on data from the last census of the general population of Cameroon; which estimated the population of Ngaoundere at about 200,000 inhabitants. The study will therefore make it possible to estimate the population actually exposed to radio diagnostics in the public sector as well as in the private sector. In accordance with the recommendations of European Commission (EC) Report No. 154 [5], the dosimetric indicator used in this study to estimate the dose to the population related to medical exposure is the effective dose $\mathrm{E}$ (expressed in milli sievert, $\mathrm{mSv}$ ) which is 
an indicator of the risk of health detriment linked to individual exposure to ionizing radiation. Being a standardized indicator, it allows comparisons between different countries and study of the evolution of the exposure that results from this or that type of act over time. Effective doses were calculated using the conversion factor values defined in ICRP Publication 60 [7]. From the number of $N t$ acts and the average effective dose associated with each type of act $t$, it is possible to calculate the collective effective dose $S=\Sigma E t \times N t$ [8]. The annual average effective dose per inhabitant is obtained by dividing the collective effective dose $S$ by the total population size for the year studied, whether or not exposed to ionizing radiation. The statistical analysis was carried out using the software sphinx V5, Excel 2016 and the effective dose was calculated from the Internet Dose calculation Module (MICADO) online software of the National Institute for Radioprotection and Nuclear Safety (NIRNS) of France.

\section{Results}

1) Total number of acts and collective effective dose for the population of Ngaoundéré in 2018

It is estimated that 4136 diagnostic procedures were performed in Ngaoundéré from January to December 2018. Of the 4030 patients, of whom 2394 (59.4\%) were men and 1636 (40.6\%) women, the sex ratio was $\mathrm{M} / \mathrm{W}$ of 1.5 (Figure 1) and an average act number of 0.02 per inhabitant, $2.07 \%$ of the population of Ngaoundere performed at least one conventional imaging examination in 2018, so $0.84 \%$ women and $1.22 \%$ of men. The mean age was $37 \pm 19.25$ years with 1 month and 96 years extremes, the most represented age groups were 30 - 34 years with $378(9.13 \%)$ cases, 35 - 39 years with 298 (7.20\%) cases, 25 - 29 years with $266(6.43 \%)$ cases, 40 - 44 years with $216(5.22 \%)$ cases, 45 - 49 years with $214(5.17 \%)$ cases, and 20 - 24 years with 202 (4.88\%) cases (Table 1). The age group performing the most examination in men is 25 - 49 years and 25 - 54 years in the women.

2) Distribution of acts and collective effective dose by anatomical area explored

The most frequent acts involved the thorax, limbs, spine and pelvis with respectively $53.8 \% ; 19.6 \% ; 14.3 \%$ and $6.7 \%$ (Table 2 ). The acts involving the spine

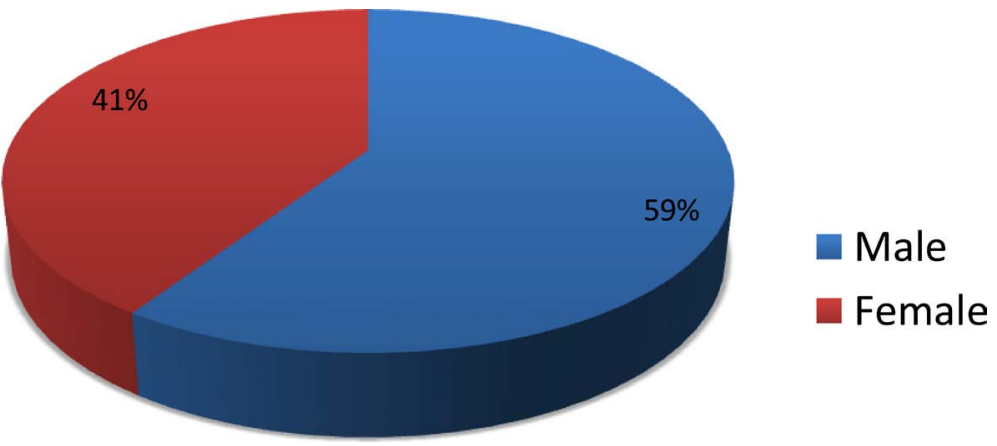

Figure 1. Distribution of acts performed by sex. 
Table 1. Distribution of number of acts performed by sex and age.

\begin{tabular}{|c|c|c|c|}
\hline \multirow{2}{*}{ Age group } & \multicolumn{3}{|c|}{ Sex } \\
\hline & Male & Female & Total \\
\hline $0-1$ & $16(0.39 \%)$ & $28(0.68 \%)$ & $44(1.06 \%)$ \\
\hline $1-8$ & $50(1.21 \%)$ & $38(0.92 \%)$ & $88(2.13 \%)$ \\
\hline $5-9$ & $44(1.06 \%)$ & $50(1.21 \%)$ & $94(2.27 \%)$ \\
\hline $10-14$ & $64(1.55 \%)$ & $50(1.21 \%)$ & $114(2.76 \%)$ \\
\hline $15-19$ & $72(1.74 \%)$ & $38(0.92 \%)$ & $110(2.66 \%)$ \\
\hline $20-24$ & $140(3.38 \%)$ & $62(1.50 \%)$ & $202(4.88 \%)$ \\
\hline $25-29$ & $172(4.16 \%)$ & $94(2.27 \%)$ & $266(6.43 \%)$ \\
\hline $30-34$ & 252 (6.09\%) & $126(3.05 \%)$ & $378(9.13 \%)$ \\
\hline $35-39$ & $176(4.26 \%)$ & $122(2.95 \%)$ & $298(7.21 \%)$ \\
\hline $40-44$ & $154(3.72 \%)$ & $62(1.50 \%)$ & $216(5.22 \%)$ \\
\hline $45-49$ & $138(3.34 \%)$ & $76(1.84 \%)$ & $214(5.17 \%)$ \\
\hline $50-54$ & $76(1.84 \%)$ & $78(1.89 \%)$ & $154(3.72 \%)$ \\
\hline $55-59$ & $82(1.98 \%)$ & $52(1.26 \%)$ & $134(3.24 \%)$ \\
\hline $60-64$ & $100(2.42 \%)$ & $68(1.64 \%)$ & $168(4.06 \%)$ \\
\hline $65-69$ & $40(0.97 \%)$ & $34(0.82 \%)$ & $74(1.79 \%)$ \\
\hline $70-74$ & $40(0.97 \%)$ & $20(0.48 \%)$ & $60(1.45 \%)$ \\
\hline $75-79$ & $10(0.24 \%)$ & $24(0.68 \%)$ & $38(0.92 \%)$ \\
\hline $80-84$ & $18(0.44 \%)$ & $18(0.44 \%)$ & $36(0.87 \%)$ \\
\hline $85-89$ & $12(0.29 \%)$ & $8(0.19 \%)$ & $20(0.48 \%)$ \\
\hline $90-94$ & $6(0.15 \%)$ & $4(0.10 \%)$ & $10(0.24 \%)$ \\
\hline 95- & $2(0.05 \%)$ & $2(0.05 \%)$ & $4(0.1 \%)$ \\
\hline Unknown & $792(19.14 \%)$ & $620(14.99 \%)$ & $1412(34.14 \%)$ \\
\hline TOTAL & 2457 (59.40\%) & $1679(40.60 \%)$ & $4136(100 \%)$ \\
\hline
\end{tabular}

(lumbar and cervical spine), pelvic (basin, hip and hysterosalpingography (HSG)), skull and abdomen (intravenous urography, barium enema (BE) and abdomen without preparation (AWP)) contributed to the majority of the collective effective dose with $45.75 \%, 25.96 \%, 10.53 \%$ and $8.84 \%$ respectively, the total effective dose $\mathrm{S}$ resulting from all the acts is equal to $8300 \mathrm{mSv}$ (Table 3).

\section{3) The most frequent acts by sex and age}

Table 4 and Figures 2-6 present the distribution of examinations by anatomical region and age group, it appears that chest and spine radiography is performed at all ages with a predominance between 20 and 64 years whatever the sex, $\mathrm{x}$-rays of limbs predominate between 1 and 69 years, pelvis between 20 and 54 years old. Under 15 years old $\mathrm{x}$-rays concerning the pelvis are rare and almost non-existent after 69 years, the same is true of $\mathrm{x}$-rays of skulls that predominate between 20 and 39 years, beyond these age groups, they are nonexistent. We also 
observe the following information in this table and these figures: The exposure of patients under five years is primarily in the chest region with $23.52 \%$ for males and $30.88 \%$ for females. For limbs, $29.41 \%$ males and $13.23 \%$ females, and skull $2.94 \%$ males and $0 \%$ females, no pelvic $\mathrm{x}$-ray under five years. For children aged 5 to 20 years, irradiation affects the majority of limbs with $32.11 \%$ for males and $13.13 \%$ for females. For adults between 21 and 50 years old, this irradiation concerns all the most frequent acts. As early as the age of 50 years, radiation is predominant for thoracic, lumbar spine and pelvic examinations. Overall, $\mathrm{x}$-rays are more common in males than females at any age.

Table 2. Distribution of imaging by anatomical region and sex.

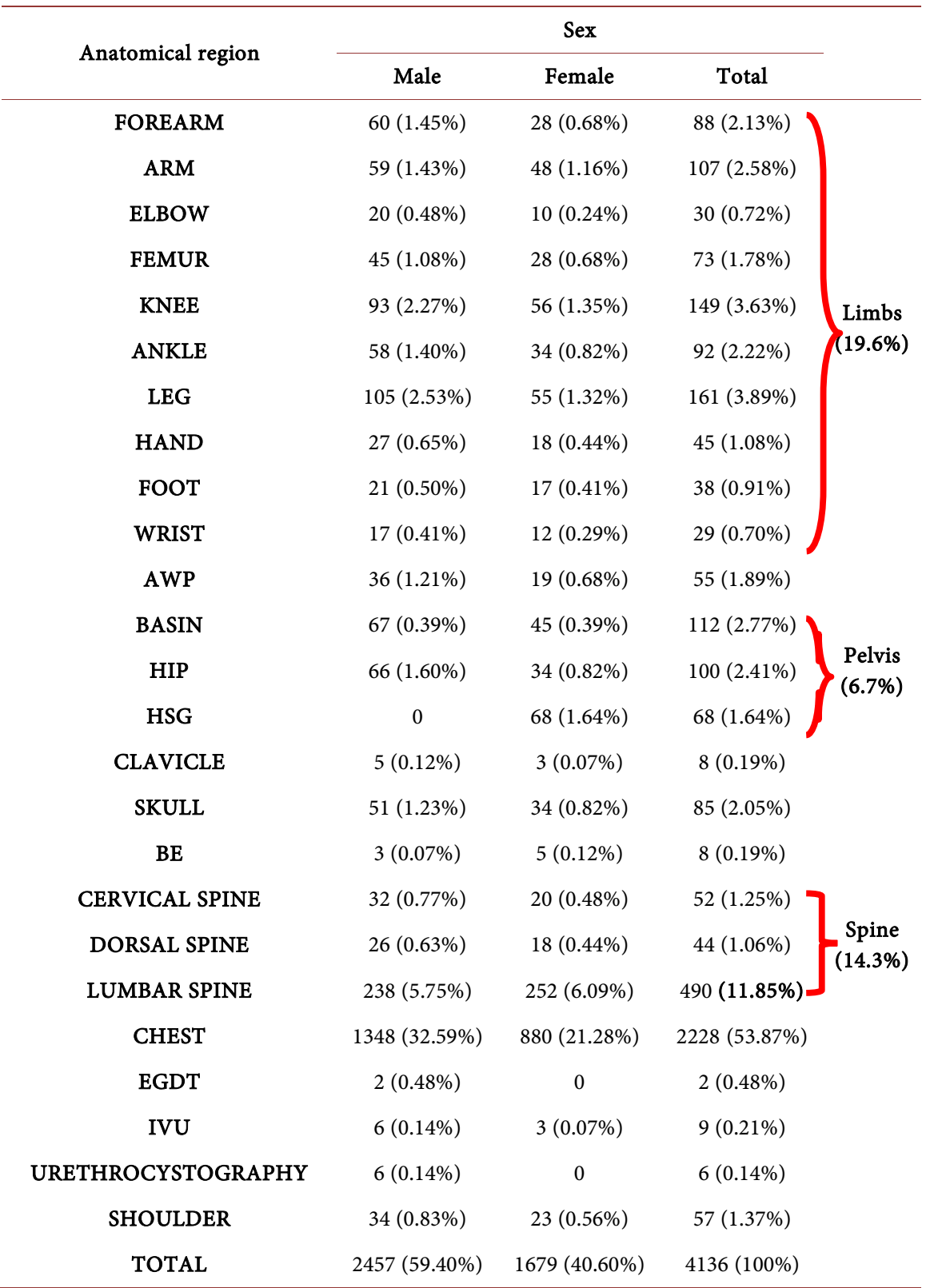

AWP: Abdomen without preparation, HSG: Hysterosalpingography, BE: Barium enema, IVU: Intravenous urography, EGDT: Esophageal and gastro duodenal transit. 
Table 3. Collective dose associated with each type of examination.

\begin{tabular}{|c|c|c|c|}
\hline EXAMS & DOSE COLLECTIVE (mSv) & \multicolumn{2}{|c|}{ Percentage } \\
\hline FORE ARM & 24.82 & $0.30 \%$ & \\
\hline ARM & 4.42 & $0.05 \%$ & \\
\hline HAND & 3.38 & $0.04 \%$ & \\
\hline FOOT & 5.56 & $0.07 \%$ & \\
\hline WRIST & 3.22 & $0.04 \%$ & Limbs \\
\hline LEG & 33.16 & $0.40 \%$ & $(1.65 \%)$ \\
\hline FEMUR & 18.16 & $0.22 \%$ & \\
\hline KNEE & 26.02 & $0.31 \%$ & \\
\hline ANKLE & 13.36 & $0.16 \%$ & \\
\hline ELBOW & 4.72 & $0.06 \%$ & \\
\hline CLAVICLE & 13.6 & \multicolumn{2}{|c|}{$0.16 \%$} \\
\hline HIP & 520.58 & $6.27 \%$ & \multirow{3}{*}{$\begin{array}{c}\text { Pelvis } \\
(25.96 \%)\end{array}$} \\
\hline HSG & 1147.62 & $13.83 \%$ & \\
\hline BASIN & 486.9 & $5.87 \%$ & \\
\hline CERVICAL SPINE & 352 & $4.24 \%$ & \multirow{3}{*}{$\begin{array}{c}\text { Spine } \\
(45.75 \%)\end{array}$} \\
\hline DORSAL SPINE & 473.54 & $5.78 \%$ & \\
\hline LUMBAR SPINE & 2967.26 & $35.75 \%$ & \\
\hline SHOULDER & 138.24 & \multicolumn{2}{|c|}{$1.67 \%$} \\
\hline URETHROCYSTOGRAPHY & 74.96 & \multicolumn{2}{|c|}{$0.90 \%$} \\
\hline EGDT & 28.50 & \multicolumn{2}{|c|}{$0.34 \%$} \\
\hline THORAX & 346.56 & \multicolumn{2}{|c|}{$4.18 \%$} \\
\hline IVU & 344.66 & $4.15 \%$ & \multirow{3}{*}{$\begin{array}{c}\text { Abdomen } \\
(8.84 \%)\end{array}$} \\
\hline BE & 254.12 & $3.06 \%$ & \\
\hline AWP & 134.98 & $1.63 \%$ & \\
\hline SKULL & 873.6 & \multicolumn{2}{|c|}{$10.53 \%$} \\
\hline TOTAL & 8300 & \multicolumn{2}{|c|}{$100 \%$} \\
\hline
\end{tabular}

AWP: Abdomen without preparation, HSG: Hysterosalpingography, BE: Barium enema IVU: Intravenous urography, EGDT: Esophageal and gastro duodenal transit.

\section{4) Average effective dose per inhabitant in Ngaoundere in 2018}

According to National Institute of Statistics (NIS) data, the population of Ngaoundere is about 200,000, which leads to an average collective effective dose of $0.04 \mathrm{mSv}$ per capita in the general population. The individual average effective dose in 2018 for the population actually exposed (2.07\% of the total population) is $2 \mathrm{mSv}$, according to sex $2.67 \mathrm{mSv}$ in women and $1.55 \mathrm{mSv}$ in men. The most irradiated age group ranges from 20 to 64 years with a dose of $4680.66 \mathrm{mSv}$ (56.39\%), the 30 - 34-year groups receive $896.76 \mathrm{mSv}(10.80 \%)$ and 35 - 39 years $706.7 \mathrm{mSv}(8.51 \%)$ (Table 5 and Figure 7). The collective dose amount per sex is 
Table 4. Distribution of the number of acts for the most frequent examinations by sex and age.

\begin{tabular}{|c|c|c|c|c|c|c|c|c|c|c|}
\hline \multirow{2}{*}{ Exams Sex } & \multicolumn{2}{|c|}{ Thorax } & \multicolumn{2}{|c|}{ Lumbar spine } & \multicolumn{2}{|c|}{ Limbs } & \multicolumn{2}{|c|}{ Pelvis } & \multicolumn{2}{|c|}{ Skull } \\
\hline & Male & Female & Male & Female & Male & Female & Male & Female & Male & Female \\
\hline $0-1$ & 8 & 18 & 0 & 0 & 6 & 8 & 0 & 0 & 2 & 0 \\
\hline $1-4$ & 24 & 24 & 0 & 0 & 34 & 10 & 0 & 0 & 2 & 0 \\
\hline $5-9$ & 4 & 30 & 2 & 2 & 22 & 10 & 4 & 0 & 0 & 2 \\
\hline $10-14$ & 24 & 16 & 2 & 2 & 32 & 12 & 0 & 4 & 4 & 0 \\
\hline $15-19$ & 24 & 20 & 2 & 2 & 34 & 14 & 4 & 0 & 2 & 0 \\
\hline $20-24$ & 70 & 24 & 14 & 6 & 40 & 8 & 4 & 8 & 10 & 8 \\
\hline $25-29$ & 112 & 52 & 8 & 8 & 40 & 12 & 12 & 12 & 6 & 6 \\
\hline $30-34$ & 190 & 62 & 20 & 18 & 40 & 10 & 6 & 14 & 6 & 0 \\
\hline $35-39$ & 126 & 80 & 8 & 26 & 24 & 16 & 0 & 16 & 4 & 2 \\
\hline $40-44$ & 108 & 30 & 16 & 12 & 20 & 10 & 6 & 2 & 2 & 0 \\
\hline $45-49$ & 60 & 46 & 22 & 18 & 24 & 8 & 8 & 2 & 2 & 4 \\
\hline $50-54$ & 44 & 48 & 8 & 6 & 18 & 8 & 10 & 2 & 0 & 2 \\
\hline $55-59$ & 50 & 16 & 8 & 10 & 8 & 22 & 6 & 0 & 2 & 2 \\
\hline $60-64$ & 54 & 34 & 6 & 12 & 18 & 4 & 10 & 6 & 0 & 0 \\
\hline $65-69$ & 20 & 16 & 0 & 6 & 6 & 12 & 2 & 0 & 0 & 0 \\
\hline $70-74$ & 22 & 16 & 10 & 4 & 6 & 0 & 2 & 2 & 0 & 0 \\
\hline $75-79$ & 10 & 12 & 6 & 6 & 0 & 2 & 0 & 2 & 0 & 0 \\
\hline $80-84$ & 18 & 18 & 2 & 0 & 0 & 0 & 2 & 2 & 2 & 2 \\
\hline $85-89$ & 10 & 4 & 2 & 0 & 0 & 2 & 0 & 0 & 0 & 0 \\
\hline $90-94$ & 6 & 4 & 2 & 0 & 0 & 0 & 0 & 0 & 0 & 0 \\
\hline 95- & 0 & 2 & 0 & 0 & 0 & 0 & 0 & 0 & 0 & 0 \\
\hline Empty & 374 & 296 & 100 & 114 & 320 & 242 & 70 & 74 & 66 & 44 \\
\hline Total & 2228 & 868 & 490 & 252 & 924 & 410 & 280 & 146 & 182 & 72 \\
\hline
\end{tabular}

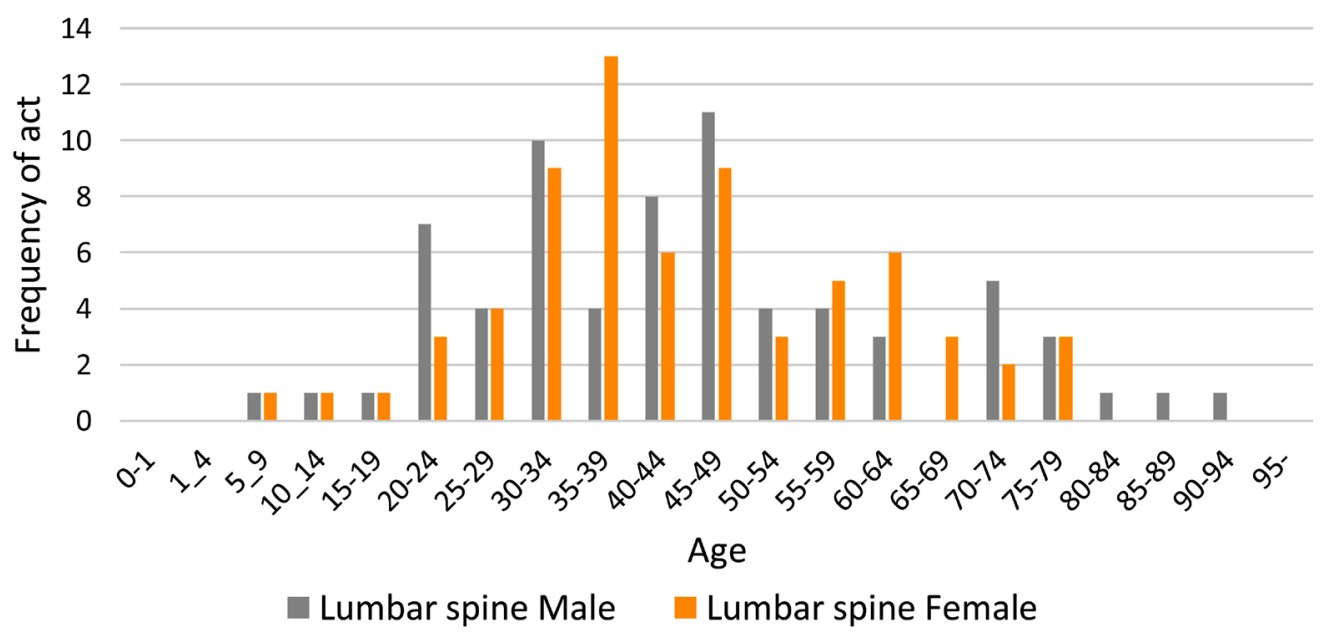

Figure 2. Distribution of the number of lumbar spine acts by age and sex. 


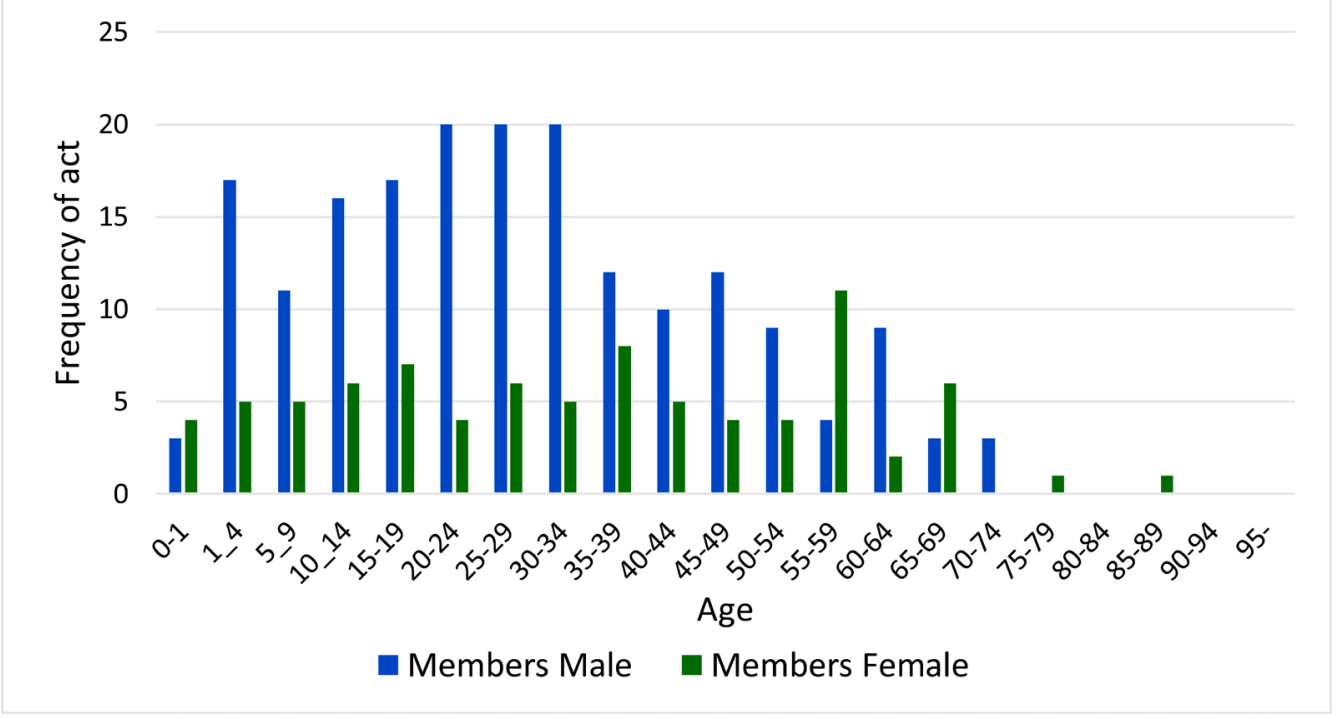

Figure 3. Distribution of number of limbs acts by sex and age.

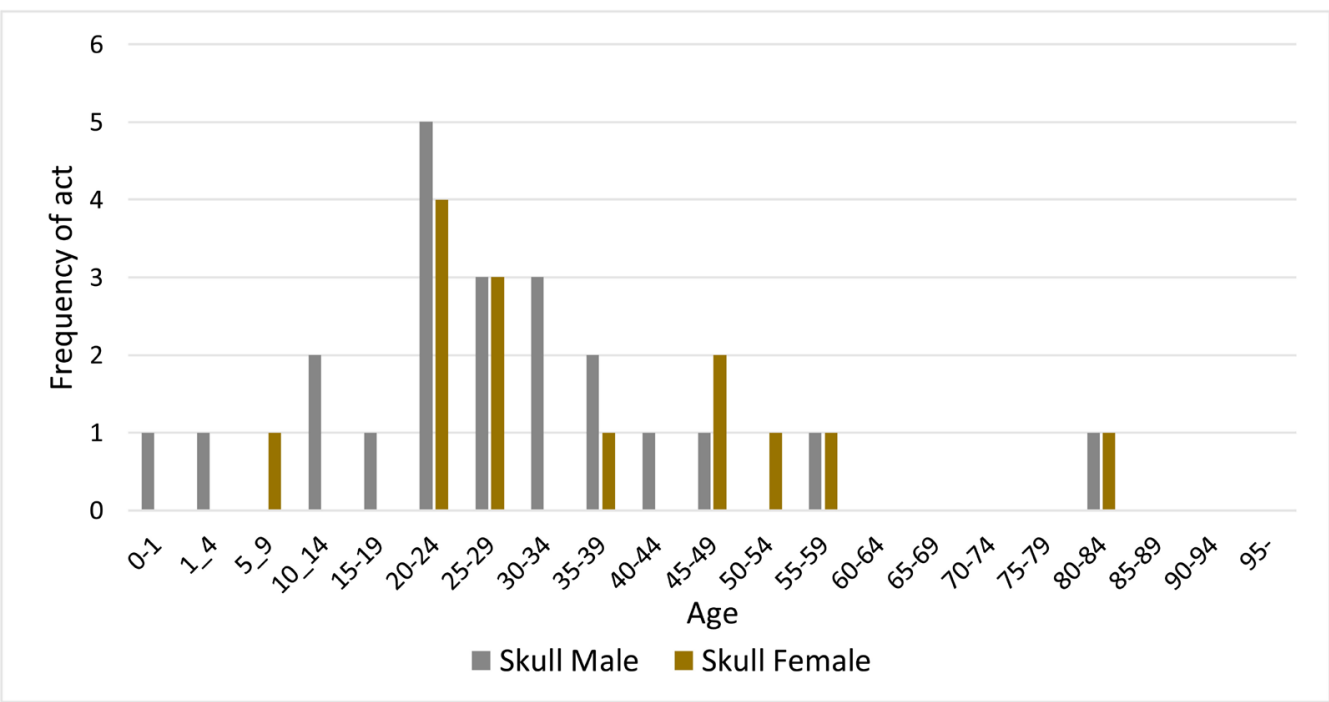

Figure 4. Skull acts number distribution by age and sex.

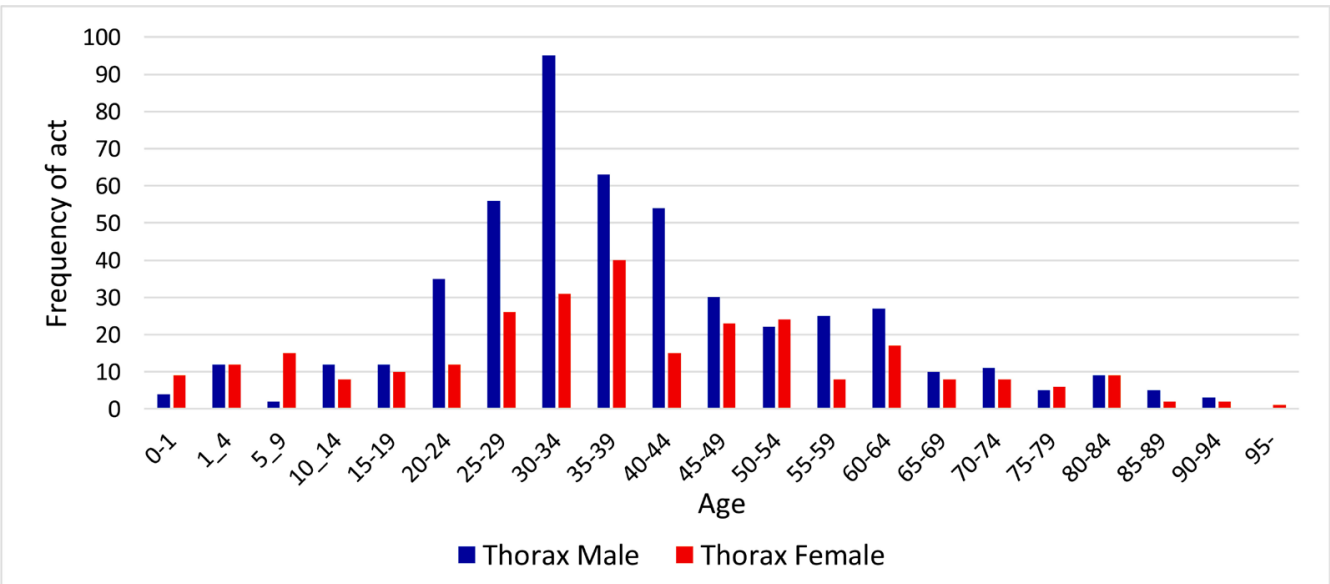

Figure 5. Distribution of the number of thorax acts by sex and age. 


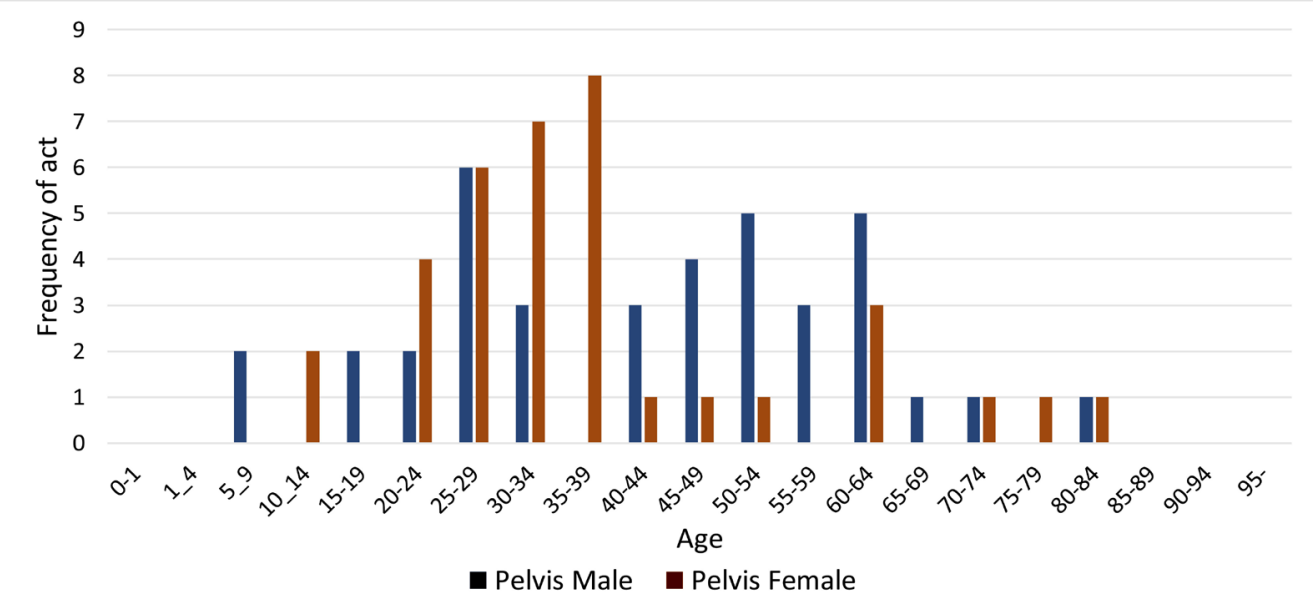

Figure 6. Distribution of number of pelvis acts by sex and age.

Table 5. Distribution of collective effective dose by sex and age.

\begin{tabular}{|c|c|c|c|c|c|c|}
\hline \multirow{3}{*}{$\begin{array}{c}\text { Age group } \\
0-1\end{array}$} & \multicolumn{4}{|c|}{ Dose (mSv) } & \multirow{2}{*}{\multicolumn{2}{|c|}{ Total }} \\
\hline & \multirow{2}{*}{$\begin{array}{c}\text { Male } \\
4.76\end{array}$} & \multicolumn{3}{|c|}{ Female } & & \\
\hline & & $0.06 \%$ & 7.06 & $0.09 \%$ & 11.82 & $0.14 \%$ \\
\hline $1-4$ & 17.98 & $0.22 \%$ & 8.3 & $0.1 \%$ & 26.28 & $0.31 \%$ \\
\hline $5-9$ & 32.58 & $0.39 \%$ & 17.02 & $0.21 \%$ & 49.6 & $0.60 \%$ \\
\hline $10-14$ & 42.3 & $0.51 \%$ & 109.66 & $1.32 \%$ & 151.96 & $1.83 \%$ \\
\hline $15-19$ & 51.98 & $0.63 \%$ & 28.44 & $0.34 \%$ & 80.42 & $0.97 \%$ \\
\hline $20-24$ & 151.7 & $1.83 \%$ & 317.18 & $3.82 \%$ & 468.88 & $5.65 \%$ \\
\hline $25-29$ & 218.68 & $2.63 \%$ & 365.78 & $4.41 \%$ & 584.46 & $7.04 \%$ \\
\hline $30-34$ & 340.3 & $4.1 \%$ & 556.46 & $6.70 \%$ & 896.76 & $10.80 \%$ \\
\hline $35-39$ & 324.32 & $3.91 \%$ & 382.38 & $4.61 \%$ & 706.7 & $8.51 \%$ \\
\hline $40-44$ & 231.7 & $2.79 \%$ & 198.16 & $2.39 \%$ & 429.86 & $5.18 \%$ \\
\hline $45-49$ & 340.92 & $4.1 \%$ & 243.66 & $2.94 \%$ & 584.58 & $7.04 \%$ \\
\hline $50-54$ & 237.08 & $2.86 \%$ & 100.32 & $1.21 \%$ & 337.4 & $4.07 \%$ \\
\hline $55-59$ & 161.18 & $1.94 \%$ & 135.38 & $1.63 \%$ & 296.56 & $3.57 \%$ \\
\hline $60-64$ & 197.12 & $2.37 \%$ & 178.34 & $2.15 \%$ & 375.46 & $4.52 \%$ \\
\hline $65-69$ & 58.042 & $0.70 \%$ & 27.82 & $0.34 \%$ & 85.86 & $1.03 \%$ \\
\hline $70-74$ & 109.86 & $1.32 \%$ & 38.02 & $0.46 \%$ & 147.88 & $1.78 \%$ \\
\hline $75-79$ & 19.38 & $0.23 \%$ & 96.06 & $1.16 \%$ & 115.44 & $1.39 \%$ \\
\hline $80-84$ & 32.94 & $0.40 \%$ & 30.7 & $0.37 \%$ & 63.64 & $0.77 \%$ \\
\hline $85-89$ & 15.76 & $0.19 \%$ & 0.98 & $0.012 \%$ & 16.74 & $0.20 \%$ \\
\hline $90-94$ & 13.52 & $0.16 \%$ & 0.50 & $0.01 \%$ & 14.02 & $0.17 \%$ \\
\hline 95- & 29.94 & $0.36 \%$ & 12.6 & $0.15 \%$ & 42.54 & $0.51 \%$ \\
\hline Empty & 1180 & $14.22 \%$ & 1632.4 & $19.67 \%$ & 2812.4 & $33.88 \%$ \\
\hline TOTAL & 3812.96 & $45.94 \%$ & 4487.22 & $54.06 \%$ & 8300 & $100 \%$ \\
\hline
\end{tabular}




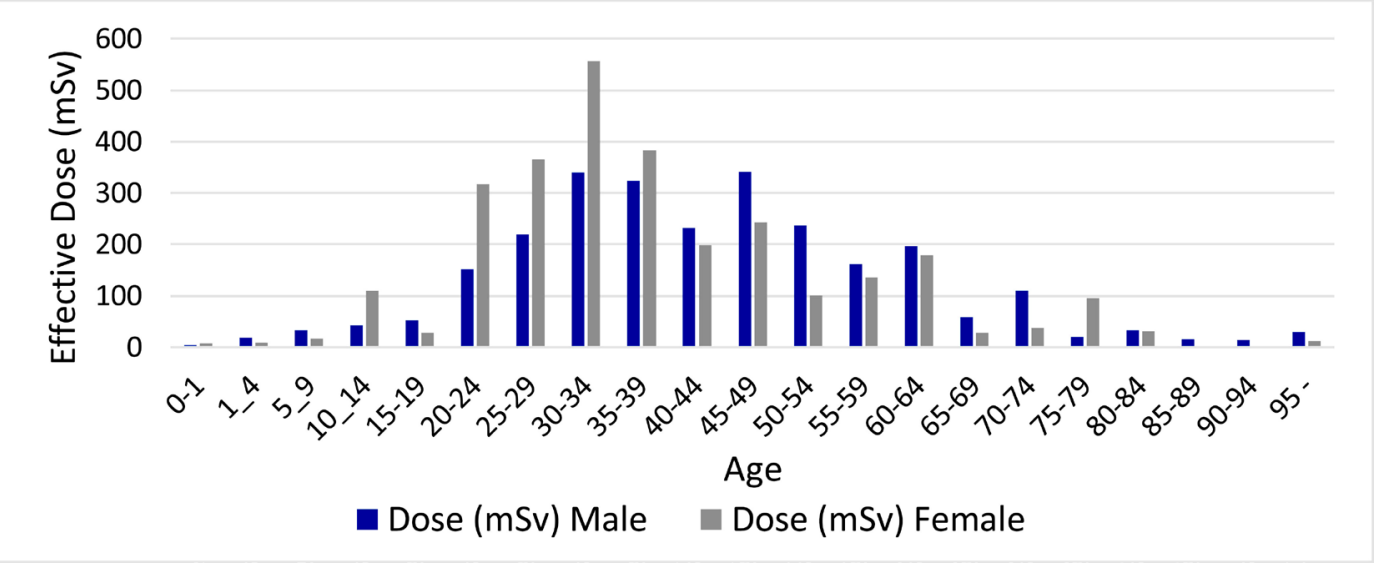

Figure 7. Distribution of collective effective dose by sex and age.

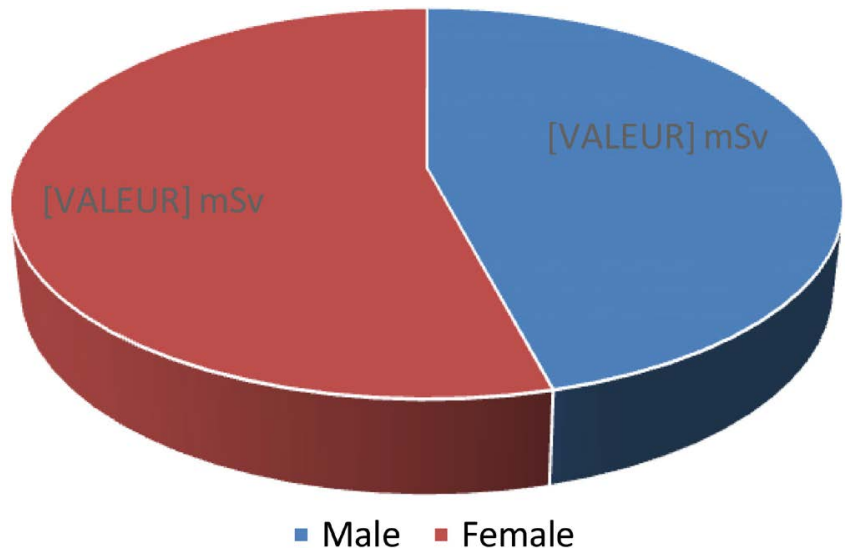

Figure 8. Collective effective dose by sex.

higher among women with $4487.20 \mathrm{mSv}$ (54.06\%) than men with $3812.98 \mathrm{mSv}$ (45.94\%) (Figure 8).

\section{Discussion}

\section{1) Frequency of act}

The number of conventional radiology acts per anatomical region per 1000 inhabitants in Ngaoundéré in 2018 is 20.68, which is lower than those achieved in France with 744 acts in 2007; Switzerland 762 acts in 1998; Norway 742 acts in 2002; Germany with 1080 acts in 2003, Belgium with 1160 acts in 2001 and the United States with 1033 acts in 2006 [8]. Indeed, the development of medical imaging is recent in the city of Ngaoundere, many equipments are outdated, operating intermittently. The high price of imaging exams relative to the average income of populations is a handicap to examinations. The low number of these examinations also makes it possible to limit the irradiation of the population. Imaging is varied across all anatomical regions with predominance of the thorax which accounts for more than half of the acts with $53.9 \%$ followed by limbs with $19.6 \%$ and the lumbar spine with $11.85 \%$. Specialized examinations are very rare, hysterosalpingography (HSG) is $1.64 \%$, intravenous urography (IVU) $0.34 \%$, ba- 
rium enema (BE) $0.29 \%$, urethrocystography $0.15 \%$ and esophageal and gastro duodenal transit (EGDT) $0.05 \%$.The high frequency of an act takes into account its involvement in the management of common pathologies, this is the case of chest $\mathrm{x}$-ray whose involvement in the management of pulmonary, cardio-mediastinal and costal pathologies is no longer to demonstrate. In addition this examination is strongly realized within the framework of the pre employment visits, the systematic medical visits and even the visits before the registration in universities, the granting of a visa to travel in certain countries [9] which is not the case for examinations such as limbs, spine, skull whose indications are more specific and limited, often occurring in cases of trauma, pain and lameness.

Our data are similar to those of France recorded in the National institute of Health and Medical Research report of 1994 [10] where the chest X-ray represents $31 \%$, followed by the spine of $8.3 \%$. As for the specialized exams, their request is rather weak because of the absence in our city of the specialists being able to request these examinations; more over they are rather expensive. Chest $\mathrm{x}$-rays are found at all ages, with the limbs predominantly 0 - 5 years old, the pelvis predominating in adolescents up to 50 years, and the lumbar spine predominantly at the age of 50 years and more. The distribution of $x$-rays according to the age marries the pathologies which concern these age groups, the thoracic pathologies are found at all the ages, those of the limbs concern the children and the young adults, the pelvis and the lumbar spine mainly concern the adults. Our data corroborate those of Switzerland [11] where $\mathrm{x}$-rays in patients under five years mainly concern the thorax region, for children aged five years and above mainly limbs and joints, for adults under 50 years of age this radiation also mainly affects limbs followed by the chest, from 50 years it is again the thorax that dominates.

\section{2) Effective dose}

The amount of collective dose per sex is higher among women with a total of $4487.22 \mathrm{mSv}$ (54.06\%) compared to men with a total of $3812.96 \mathrm{mSv}$ (45.94\%). Among the most irradiating examinations are the lumbar spine and the pelvis, these are examinations concerning thick areas and composed of very dense structures that require a significant load in terms of kilo voltage and milli ampere and therefore a high dose of radiation to cross them. The annual effective dose per inhabitant in Ngaoundere in 2018 of $0.04 \mathrm{mSv}$ is lower than that of the United Kingdom with $0.41 \mathrm{mSv}$, Denmark $0.46 \mathrm{mSv}$ excluding nuclear medicine, the Netherlands $0.52 \mathrm{mSv}$, Sweden $0.72 \mathrm{mSv}$, France in $20071.29 \mathrm{mSv}$, Norway $1.15 \mathrm{mSv}$ in 2002, Luxembourg $1.98 \mathrm{mSv}$ in 2002, Belgium $1.97 \mathrm{mSv}$ in 2001, Germany $1.76 \mathrm{mSv}$ in 2003, United States $3 \mathrm{mSv}$ in 2006 [8] and Switzerland $1.07 \mathrm{mSv}$ in 1998, $1.21 \mathrm{mSv}$ in 2008 and $1.42 \mathrm{mSv}$ in 2013 [11]. It should be noted that, the annual per capita effective dose in Ngaoundéré in 2018, equal to $0.04 \mathrm{mSv}$, is lower than the European and American average values and to the natural irradiation which is $2.4 \mathrm{mSv}$ [12]. This wide difference in dose can be explained by the presence of numerous radio diagnostic procedures including 
CT and nuclear medicine and a wide range of protocols by modality in these countries and also the very high number of irradiating acts in these cities compared to the city of Ngaoundere. In conventional radiology, the acts exposing the abdomen (Spine, IVU, BE and AWP), the pelvis (pelvis, hip and HSG) and the skull contribute mainly to the collective effective dose with respectively $48.83 \%$, $25.96 \%$ and $10.53 \%$ of the collective effective dose, which is the same with data from France 2007 [8] where the acts exposing the abdomen, the pelvis and the digestive tract contribute mainly to the collective dose with $41.5 \%, 29.8 \%$ and $11.8 \%$ of the collective effective dose. These are exams for which a large amount of irradiation is used and the contrast examinations are dynamic, requiring multiple incidences.

This is a pilot study that certainly has limitations, indeed this study concerns only the conventional radiography which is the only modality currently practiced in our city because the only scanner installed is non-functional, which can underestimate the dose radiation received by the population. This study is also performed in a single city so little representative. The lack of a system of automatic collection of doses like Dosewach or PCXMA can also be a limit which has forced us to make a manual calculation of doses. This study has the merit to give the distribution of examinations by anatomical region, age and sex, it also gives an idea of the dose of radiation of medical origin received by the patients and the whole population, and this can be a basis for follow-up for this population.

\section{Conclusion}

At the end of this study, it appears that, the medical exposure to ionizing radiation in Ngaoundere in 2018 is mainly done by conventional radiology; the total number of examinations is 4136 , the average number of acts of 0.02 act per inhabitant; the examinations are more frequently performed in men and the irradiation is more important for women; the most affected age groups are those aged 25 to 49 years for men and 25 to 54 years for women. The most common examinations are the thorax, the limbs, the lumbar spine and the skull; the most radiating examinations are the lumbar spine, the abdomen and the pelvis. The collective effective dose is $8300 \mathrm{mSv}$ with $4487.22 \mathrm{mSv}$ in women and 3812.96 $\mathrm{mSv}$ in men, an effective average dose per capita of $0.04 \mathrm{mSv}$ well below European, US and natural irradiation values. The proportion of the population that has actually benefited from a conventional radiology examination is $2.07 \%$, an individual effective average dose of $2 \mathrm{mSv}$ per person.

\section{Conflicts of Interest}

The authors declare that there is no conflict of interests regarding the publication of this paper.

\section{References}

[1] Rannou, A., Aubert, B. and Scanff, P. (2006) Exposure of the French Population to 
Ionizing Radiation. Report IRSN/DRPH/SER 2006-02.

https://www.irsn.fr/FR/Pages/Home.aspx

[2] National Council on Radiation Protection and Measurements (2009) Ionizing Radiation Exposure of the Population of the United States. NCRP Report $n^{\circ} 160$.

https://www.ncbi.nlm.nih.gov/

[3] Directive 97/43/Euratom of 30 June 1997, on the Protection of the Health of Persons against the Dangers of Ionizing Radiation When Exposed for Medical Purposes. https://www.asn.fr/

[4] Directive 96/29/Euratom of 13 May 1996 Laying down Basic Standards for the Protection of the Health of Workers and the General Public against the Dangers Arising from Ionizing Radiation. https://www.asn.fr/

[5] European Commission, DG Energy-Transport (2008) European Guidance on Estimating Population Doses from Medical X-Ray Procedures, Radiation Protection $\mathrm{n}^{\circ}$ 154.

[6] République du Cameroon (2002) Décree n² 2002/250 of 31 October 2002 Establishing, Organisation and Operating the National Radiation Protection Agency. https://www.ilo.org/global/lang--en/index.htm

[7] International Commission on Radiological Protection (1990) Recommandation of the International Commission on Radiological Protection. Publication 60 of the CIPR French Language Edition, Pergamon Press, Oxford. https://www.asn.fr/

[8] Cecile, E., Sandra, S. and Bernard, A. (2012) Exposure of the French Population to Ionizing Radiation Related to the Medical Diagnostic Procedures in 2007-Institut de Veille Sanitaire. https://www.irsn.fr/FR/Pages/Home.aspx

[9] Boniface, M., Joshua, T., Walter, P., Fernande, Z., Emrick, G. and Joseph, G. (2012) Assessing the Role of Routine Chest Radiography in Asymptomatic Students during Registration at a University in an Endemic Area of Tuberculosis. Annals of Tropical Medicine and Public Health, 5, 419-422. https://doi.org/10.4103/1755-6783.105122

[10] Pascale, S., Jean, D., Phillipe, P. and Bernard, A. Exposition de la population française aux rayonnements ionisants-Institut de veille sanitaire.

https://www.irsn.fr/FR/Pages/Home.aspx

[11] Le Coultre, R., Bize, J., Champendal, M., Wittwer, D., Trueb, P. and Verdun, F. (2015) Exposition de la population suisse aux rayonnements ionisants en imagerie médicale en 2013 Rapport final Juillet 2015.

https://www.bag.admin.ch/bag/de/home.html

[12] United Nation (2008) Report of the United Nations Scientific Committee on the Effects of Atomic Radiation, Fifty-Sixth Session (10-18 July 2008). General Assembly Official Records Sixty-Third Session Supplement No. 64. 